\title{
The Choke as a Brainbox for Smart Wellhead Control
}

\author{
Stanley I. Okafor, Azubuike H. Amadi, Mobolaji A. Abegunde, and Joseph A. Ajienka
}

\begin{abstract}
This project uses production data to generate well-specific correlations for GLR, BSW and sand concentration which are used for predictions. A software has been developed to effect a smart control algorithm. This results in a bean up or bean down operation depending on the current flowing conditions and constraints. Excel programming environment was used to write a code that constantly takes in measured data points, models the behavior of the individual data sets with bean size and controls the choke if the parameters of interest go above a predetermined cut-off. The software was also equipped with an inverse matrix solving algorithm that enables it to determine the choke performance constants for any set of initialization data. A set of data from field $X$ were supplied and the choke performance constants; $A$, $\mathrm{B}, \mathrm{C}, \mathrm{D}$ and $\mathrm{E}$, were found to be 10, 0.546, $0.0,1.89$ and 1.0 respectively. In addition to that, data from subsequent production operations were entered and the software was able to control the choke size to ensure that production stays below set constraints of 500, 80 and 10 in field units for GLR, BSW and sand concentration respectively. From this, it can be concluded that the software can effectively maintain the production of unwanted well effluents below their cut-offs, thereby improving oil production and the overall Net Profit Value (NPV) of a project.
\end{abstract}

Index Terms - Algorithm, Choke Performance, Smart Control, Well problems, Multiphase flow.

\section{INTRODUCTION}

Smart control involves monitoring well behavior, measuring some parameters, and taking a decision to impose a profile on the well without having to intervene physically. This requires prior installation of some necessary hardware [2]. The goal, which is to make profit means that application of this technology should be factored in at the field development stage to ensure an optimized project.

The wellhead, together with its members, aid in controlling the volume of oil which a well can produce. The rate at which a well is allowed to produce is usually being stipulated by local authorities. However, when production commences, the proposed rate may become sub-optimal. This may be due to a possible well impairment or other well problems.

Well problems make the well inefficient; causing a reduction in oil production, damaging of surface facilities,

Published on January 23, 2021

S. I. Okafor, Institute of Petroleum Studies, University of Portharcourt, Nigeria.

(e-mail: stan5865@gmail.com)

A. H. Amadi, World Bank Center for Excellence in Oilfield Chemical

Research, University of Portharcourt, Nigeria.

(e-mail: azubuikehopeamadi@gmail.com)

M. A. Abegunde, Nigerian National Petroleum Corporation, Nigeria.

(e-mail: abegundemobolaji@ ${ }^{@}$ ahoo.com)

Joseph A. Ajienka, University of Portharcourt, Nigeria.

(e-mail: joseph.ajienka@ uniport.edu.ng) increased costs from treatment of undesired fluids, and as such should be dealt with early enough. Well problems such as excessive sand, water and gas production are common in many wells. Allowing such problems to persist would negatively affect the overall Net Profit Value (NPV) of a project.

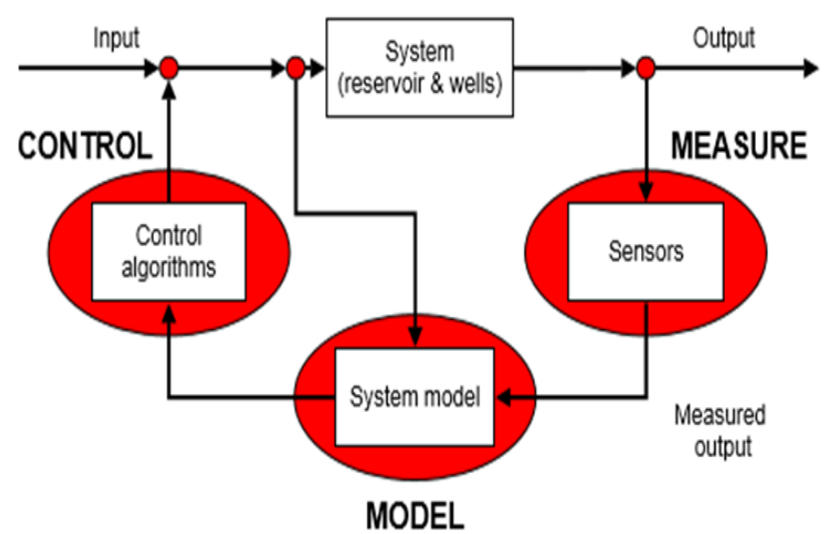

Fig. 1. Feedback control loop for oil production [2].

The wellhead here will operate with a feedback control process where surface data is continuously measured [2]. Furthermore, based on a generated model for measured variables (Basic Sediment and Water "BSW", Gas Liquid/Oil Ratio "GLR" and sand concentration) and set constraints, flow is adjusted. Available models are either too theoretical or require some parameters to be determined offfield [3], [4]. The method used here employs already acquired production data to generate and/or improve models.

The objectives of this study are:

1. To develop an algorithm for controlling the bean size so as to produce within acceptable limits.

2. To employ a cognitive technique to determine choke performance constants.

3. To develop a user-friendly software to execute the codes.

\section{MATERIALS AND METHODS}

\section{A. Research Design}

As earlier stated, the method of operation of the wellhead would be a feedback control process of constant measurement, modelling and control. However, the measurement component of the process would also be able to predict the measured variables, after which a comparison of the measured and predicted values can be made. Modelling is carried out using a developed algorithm, into which the measured/predicted values are supplied. Finally, 
the control is effected by the choke using a reactive strategy. An algorithm is developed, and a set of programs are written to execute the process.

\section{B. Data Source}

The information needed for the project was gotten from a producing well in field $\mathrm{X}$. These data are used to initialize the software and to show the effect of subsequently added data on choke correlations respectively. Production cut-offs for GLR, BSW and sand concentration used in this study are listed in Table I.

\begin{tabular}{cc}
\multicolumn{2}{c}{ TABLE I: COMMON CUT-OFFS FOR DIFFERENT VARIABLES } \\
\hline \hline Dependent Variable & Cut-offs \\
\hline GLR (Gas-Liquid Ratio) & $500-3000 \mathrm{cf} / \mathrm{bbl}$. \\
BSW (Basic Sediment and Water) & $80-90 \%$ \\
Sand Concentration & $10-15 \mathrm{ppb}$. \\
\hline \hline
\end{tabular}

\section{Choke Parameter Determination}

The multiphase flow equation relates production variables (GLR, Specific Gravity 'S.G' etc.) with bean size. Using the data from the production test, several relationships of different coefficients can be generated from the multiphase relationship in Equation 1 [1].

$q=\frac{P_{w h}^{E} S^{D}}{A R_{P}^{B} \gamma_{O}^{C}}$

where, $\mathrm{q}$ is production rate, $\mathrm{P}_{\mathrm{wh}}$ is wellhead pressure, $\mathrm{S}$ is bean size, $R_{p}$ is producing GLR and $\gamma_{o}$ is oil specific gravity. $\mathrm{A}, \mathrm{B}, \mathrm{C}, \mathrm{D}$ and $\mathrm{E}$ are choke performance constants.

From this, we can solve for the constants of the multiphase flow equation. However, in order to solve for these constants, they should be treated as variables in the equation. To write a program to solve such a problem, linearization of the multiphase equation is necessary. The objective here was to solve five equations simultaneously for the variables (A, B, C, D and E). The linear equations for obtaining the choke performance constants are of the form:

$\log q=E \log P_{w h}+D \log S-\log A-B \log R_{p}-C \log q \gamma_{o}$

A matrix of equations can be generated to solve for the desired variables.

\section{Model Generation and Selection}

This project utilizes the production data to develop a model for each variable to be controlled, as a function of an independent variable (i.e., the bean size).

In determining the best model, several things are taken into consideration. Firstly, the ability of the model to predict the condition of the shut in well (without the aid of the algorithm), which is zero production of effluents. For gas-oil ratio prediction, the viable models should be able to predict unstable flow conditions. Furthermore, the correlation coefficient of the relationship developed is displayed to guide the engineer in making reasonable decisions. A correlation coefficient of unity means that the model gives accurate predictions of the dependent variable while that of zero means that no correlation exists between variables.

\section{E. Method of Data Analysis}

To test the viability of the software to control the flow rates of effluents, the calculated/estimated parameters after adjusting the bean size are compared to their corresponding actual/measured values using tables, plots etc. The standard deviation, error margins and other important statistical parameters are computed. Also, the correlation coefficients of the generated correlations are computed. The relationships for calculating the statistical parameters are displayed from Equations 3 to 7 .

$$
\begin{aligned}
& \mathrm{PD}=\frac{\mathrm{E}-\mathrm{M}}{\mathrm{M}} \times 100 \\
& A P D=\frac{1}{n} \sum_{i=1}^{n} P D_{i}
\end{aligned}
$$

$S D=\frac{1}{n} \sqrt{n \sum_{i=1}^{n}\left(P D_{i}\right)^{2}-\left[\sum_{i=1}^{n} P D_{i}\right]^{2}}$

$$
R=\frac{\left[n \sum_{i=1}^{n}(E \cdot M)\right]-\left[\left(\sum_{i=1}^{n} E\right)\left(\sum_{i=1}^{n} M\right)\right]}{\sqrt{\left[\left(n \sum_{i=1}^{n} E^{2}\right)-R\left(\sum_{i=1}^{n} E\right)^{2}\right]\left[\left(n \sum_{i=1}^{n} M^{2}\right)-\left(\sum_{i=1}^{n} M\right)^{2}\right]}}
$$

where PD is percentage difference, APD is average percentage difference, AAPD is average absolute percentage difference, $S D$ is standard deviation, ' $R$ ' is correlation coefficient, ' $E$ ' means expected, ' $M$ ' means measured and ' $\mathrm{n}$ ' represents number of $\mathrm{PD}$ values.

\section{F. Algorithm}

The program works by following the instructions shown in the flowchart in Fig. 2.

\section{RESULTS AND DISCUSSION}

\section{A. Research and Analysis}

The steps described previously have been implemented and a software has been developed. The software is capable of executing the algorithm, performing arithmetic calculations, displaying plots and predicting choke performance constants.

The choke performance constants for a set of data are presented in this section. This is followed by an analysis of the possible models for describing the production parameters of interest. Also, the effect of the smart control on production (which is simulated by inputting a new set of data) is analyzed. Finally, the transition of selected models (i.e., model update) as a result of inputting new data (Big data) is shown. 


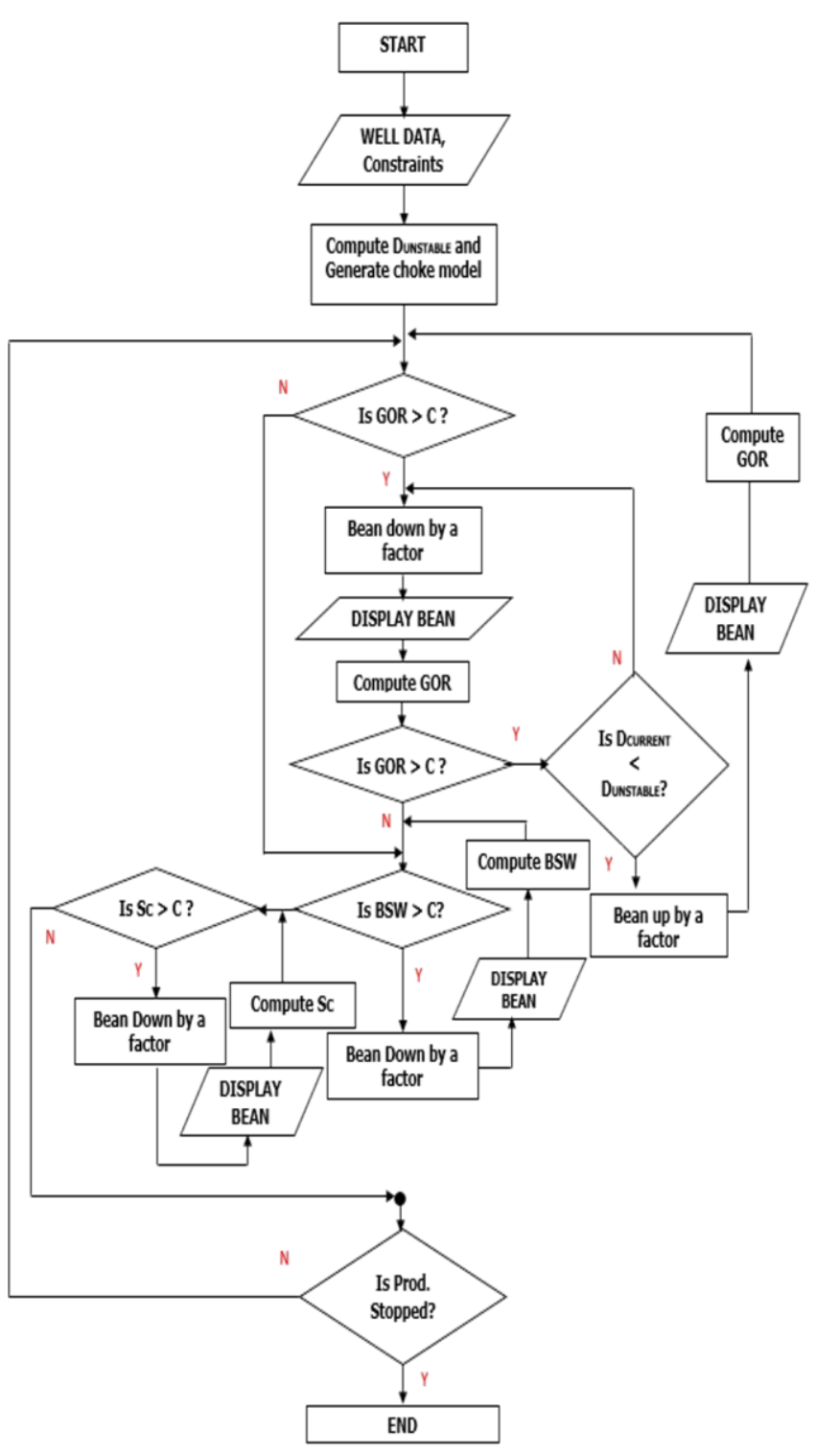

Fig. 2. Developed Algorithm.

\section{B. Choke Performance Constants}

The multiphase flow parameters for the data from field $\mathrm{X}$ were used to solve for the choke performance constants. The results are presented in Table II.

TABLE II: CHOKE PERFORMANCE CONSTANTS FOR DATA SET

\begin{tabular}{ccccc}
\hline \hline Constant & $\mathrm{A}$ & $\mathrm{B}$ & $\mathrm{C}$ & $\mathrm{D}$ \\
\hline Valve & 10.00 & 0.546 & 0.00 & 1.8899 \\
\hline
\end{tabular}

\section{Models}

The graphical plots for the different models are displayed in Appendix A.

1. Model Selection for GLR

The polynomial model was selected for predicting the GLR values since the statistical parameters show that it has the least deviation and since it gives the best representation for both stable and unstable flow. The results of the statistical parameters are displayed in Table A-1.

2. Model Selection for BSW

The power model was selected for predicting the BSW values since the statistical parameters show that it has the least deviation and since it gives a good representation of the shut in condition of the well. The results of the statistical parameters are displayed in Table A-2.

3. Model Selection for Sand Concentration

The power model was selected for predicting the BSW values since it has good statistical parameters gives a good representation of the shut in condition of the well. The results of the statistical parameters are displayed in Table A3.

\section{Effect of Automation}

The effect of the smart wellhead software on production was tested on new set of data points, assuming cut-off values of $500 \mathrm{cf} / \mathrm{bbl} ., 80 \%$ and $10 \mathrm{ppb}$ for GLR, BSW and sand concentrations respectively. The graphical plots for the new set of data are displayed in Appendix B.

1. Effect on GLR

To test for GLR, it was assumed that the BSW and sand concentrations were below their cut-offs so as to see the effect of automation on the choke size due to GLR constraints. The results for the operation are shown in Table B-1.

2. Effect on BSW

To test for BSW, it was assumed that the GLR and sand concentrations were below their cut-offs so as to see the effect of automation on the choke size due to BSW constraints. The results for the operation are shown in Table B-2.

3. Effect on Sand Concentration

To test for sand concentration, it was assumed that the BSW and GLR were below their cut-offs so as to see the effect of automation on the choke size due to sand constraints. The results for the operation are shown in Table B-3.

\section{E. Effect of New Data on Models}

The new data point was entirely entered into the software and this resulted in an alteration of the previous initialization model. This alteration is reflected in the constants of the mathematical model of the parameters of interest. The results are displayed in Table III.

TABLE III: EFFECT OF NEW DATA ON MODEL CONSTANTS

\begin{tabular}{ccccc}
\hline \hline Model & Constant & Old & New & $|\mathrm{PD}|(\%)$ \\
\hline \multirow{3}{*}{ GRL } & $\mathrm{C}_{1}$ & 2.5356 & 4.0438 & 59.48 \\
& $\mathrm{C}_{2}$ & -92.1253 & -191.4531 & 107.82 \\
& $\mathrm{C}_{3}$ & 1013.1598 & 2475.9370 & 144.38 \\
BSW & $\mathrm{C}_{1}$ & 0.0545 & 0.1413 & 159.27 \\
& $\mathrm{C}_{2}$ & 1.9429 & 1.6590 & 14.61 \\
Sand & $\mathrm{C}_{1}$ & 0.0007 & 0.0046 & 557.14 \\
Concentration & $\mathrm{C}_{2}$ & 2.8042 & 2.2664 & 19.18 \\
\hline \hline
\end{tabular}

\section{CONCLUSION}

As a result of the work carried out in this project, an excel-based software capable of controlling well fluids without any need for physical intervention (of choke) was developed. The software was equipped with some minor calculative prowess including the determination of choke performance constants. The link for understanding the framework of the software build-up is shown below: https://drive.google.com/drive/folders/1mkqHEXMKpM7o4 UqmIMgXU-t3j8MVrxgp?usp=sharing. 
The software proved that it is possible to control well effluents using a smart and remote approach for well production.

\section{APPENDIX}

TABLE A-1: STATISTICAL PARAMETERS FOR GLR MODEL

\begin{tabular}{cccccc}
\hline \hline S/N & Models & APD & AAPD & SD & R-square \\
\hline 1 & Exponential & 3.8960 & 19.9217 & 29.3 & 0.9198 \\
2 & Linear & 1.5893 & 51.3505 & 61.8 & 0.9225 \\
3 & Logarithmic & 8.4055 & 70.8306 & 85.0 & 0.8431 \\
4 & Polynomial & 4.8667 & 14.9725 & 21.2 & 0.9953 \\
5 & Power & 5.8460 & 26.0749 & 35.1 & 0.8730 \\
\hline
\end{tabular}

TABLE A-2: STATISTICAL PARAMETERS FOR BSW MODELS

\begin{tabular}{cccccc}
\hline \hline S/N & Models & APD & AAPD & SD & R-square \\
\hline 1 & Exponential & 0.5832 & 9.8710 & 10.7 & 0.9737 \\
2 & Linear & -2.479 & 12.4328 & 15.1 & 0.9714 \\
3 & Logarithmic & -3.713 & 22.0852 & 29.9 & 0.9259 \\
4 & Polynomial & 41.139 & 41.1388 & 17.0 & 0.9884 \\
5 & Power & 0.2028 & 5.6154 & 6.14 & 0.9924 \\
\hline \hline
\end{tabular}

TABLE A-3: STATISTICAL PARAMETERS FOR SAND MODELS

\begin{tabular}{cccccc}
\hline \hline S/N & Models & APD & AAPD & SD & R-square \\
\hline 1 & Exponential & 3.4057 & 24.4166 & 26.2 & 0.9347 \\
2 & Linear & 9.5576 & 18.7136 & 34.1 & 0.9896 \\
3 & Logarithmic & -18.15 & 40.9719 & 69.3 & 0.9489 \\
4 & Polynomial & 0.1513 & 7.4494 & 11.3 & 0.9993 \\
5 & Power & 1.0684 & 13.8285 & 14.7 & 0.9794 \\
\hline \hline
\end{tabular}

TABLE B-1: THE EFFECT OF AUTOMATION ON GLR

\begin{tabular}{ccccccc}
\hline \hline S/N & $\begin{array}{c}\text { Int. Bean } \\
\text { 1/64in }\end{array}$ & $\begin{array}{c}\text { Int. GLR } \\
\text { (cf/bbl.) }\end{array}$ & $\begin{array}{c}\text { New } \\
\text { Bean } \\
1 / 64 \text { in }\end{array}$ & $\begin{array}{c}\text { Est. GLR } \\
\text { (cf/bbl.) }\end{array}$ & PD (\%) & Remark \\
\hline 1 & 8 & 1500 & 30 & 214.213 & -85.72 & Low \\
2 & 18 & 160 & 18 & 172.6453 & 7.90 & High \\
3 & 28 & 480 & 28 & 443.5253 & -7.60 & Low \\
4 & 32 & 600 & 24 & 247.9855 & -58.67 & Low \\
5 & 48 & 2500 & 27 & 363.2200 & -85.47 & Low \\
\hline \hline
\end{tabular}

TABLE B-2: THE EFFECT OF AUTOMATION ON BSW

\begin{tabular}{ccccccc}
\hline \hline S/N & $\begin{array}{c}\text { Int. Bean } \\
\text { 1/64in }\end{array}$ & $\begin{array}{c}\text { Int. GLR } \\
\text { (cf/bbl.) }\end{array}$ & $\begin{array}{c}\text { New } \\
\text { Bean } \\
\text { 1/64in }\end{array}$ & $\begin{array}{c}\text { Est. GLR } \\
\text { (cf/bbl.) }\end{array}$ & PD (\%) & Remark \\
\hline 1 & 8 & 6 & 8 & 4.6552 & -22.41 & Low \\
2 & 18 & 15 & 18 & 14.973 & -0.18 & Low \\
3 & 28 & 36 & 28 & 35.4069 & -1.65 & Low \\
4 & 32 & 44 & 32 & 45.4535 & 3.30 & High \\
5 & 48 & 93 & 36 & 56.50 & -39.25 & Low \\
\hline \hline
\end{tabular}

TABLE B-3: THE EFFECT OF AUTOMATION ON SAND

\begin{tabular}{ccccccc}
\hline \hline S/N & $\begin{array}{c}\text { Int. Bean } \\
\text { 1/64in }\end{array}$ & $\begin{array}{c}\text { Int. GLR } \\
\text { (cf/bbl.) }\end{array}$ & $\begin{array}{c}\text { New } \\
\text { Bean } \\
1 / 64 \text { in }\end{array}$ & $\begin{array}{c}\text { Est. GLR } \\
\text { (cf/bbl.) }\end{array}$ & PD (\%) & Remark \\
\hline 1 & 8 & 1 & 8 & 0.5897 & -41.03 & Low \\
2 & 18 & 1.88 & 18 & 2.5176 & 33.91 & High \\
3 & 28 & 11 & 21 & 3.8365 & -65.12 & Low \\
4 & 32 & 13.4 & 24 & 5.4630 & -59.23 & Low \\
5 & 48 & 32 & 27 & 7.8193 & -75.56 & Low \\
\hline \hline
\end{tabular}

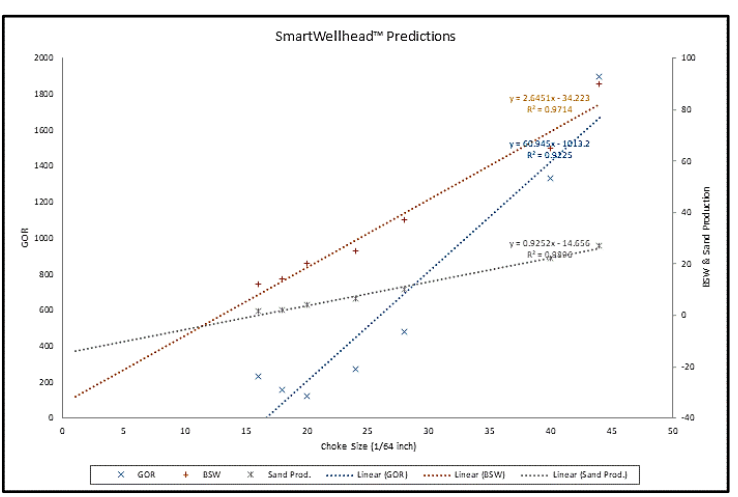

Fig. A-1. Linear plots for initialization model.

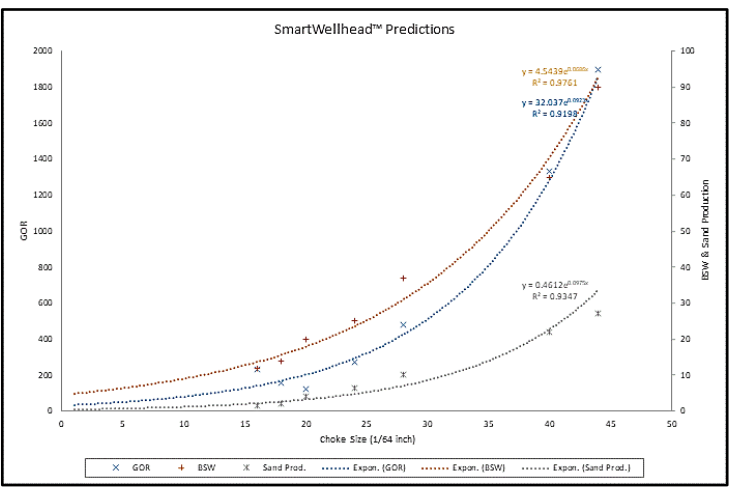

Fig. A-2. Exponential plots for initialization model.

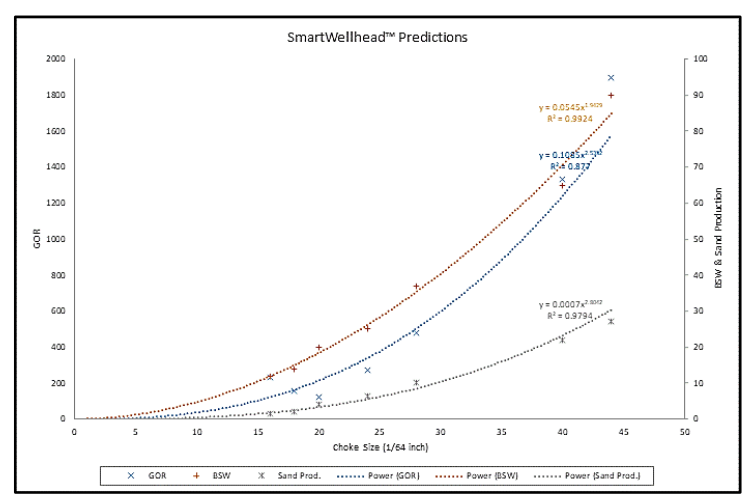

Fig. A-3. Power plots for initialization model.

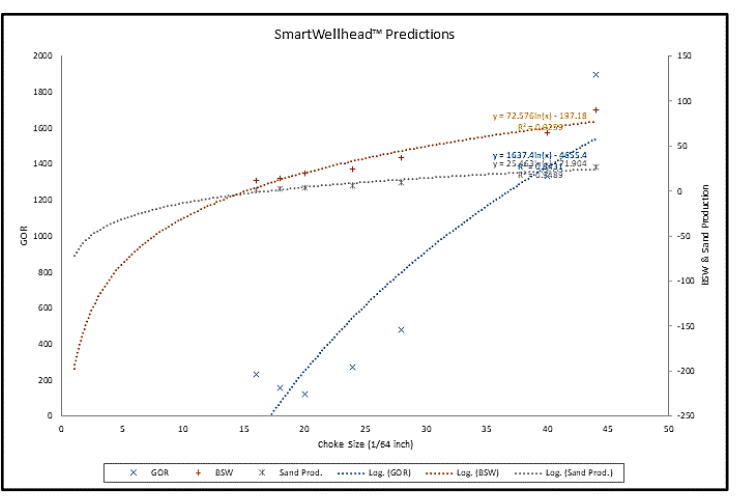

Fig. A-4. Logarithmic plots for initialization model. 


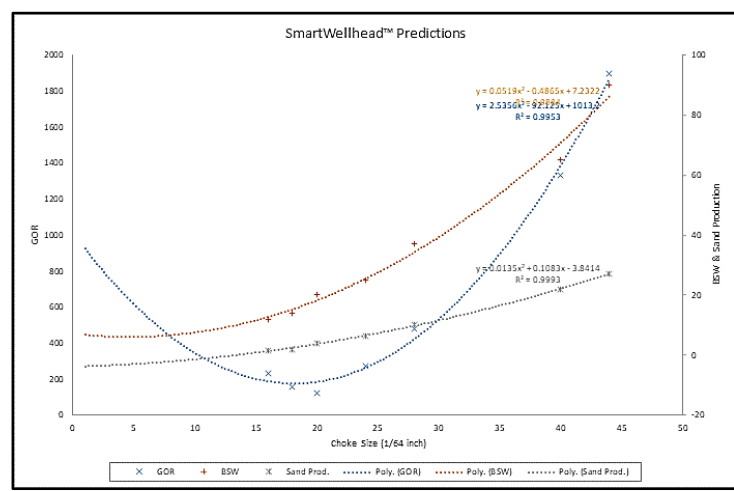

Fig. A-5. Polynomial plots for initialization model.

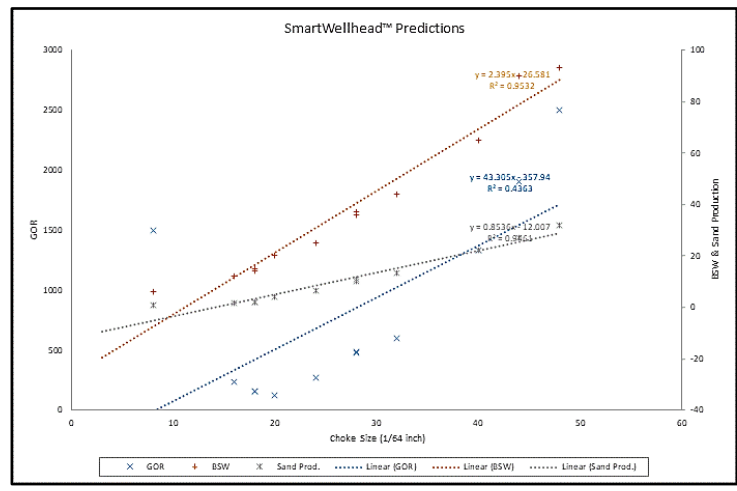

Fig. B-1. Linear plots for big data model.

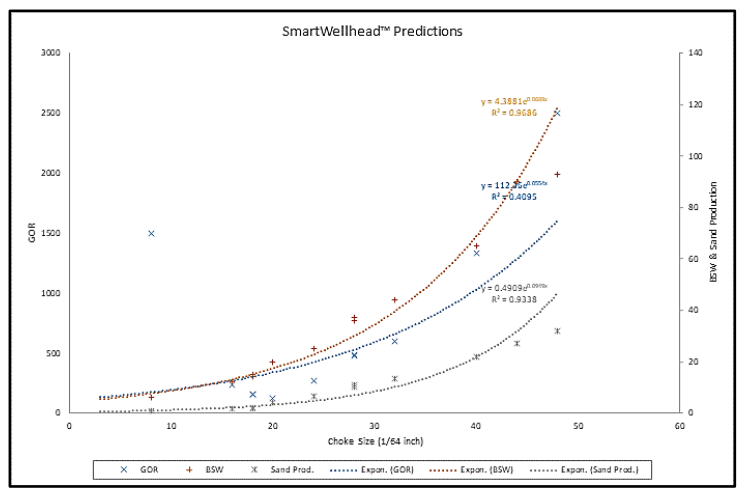

Fig. B-2. Exponential plots for big data model.

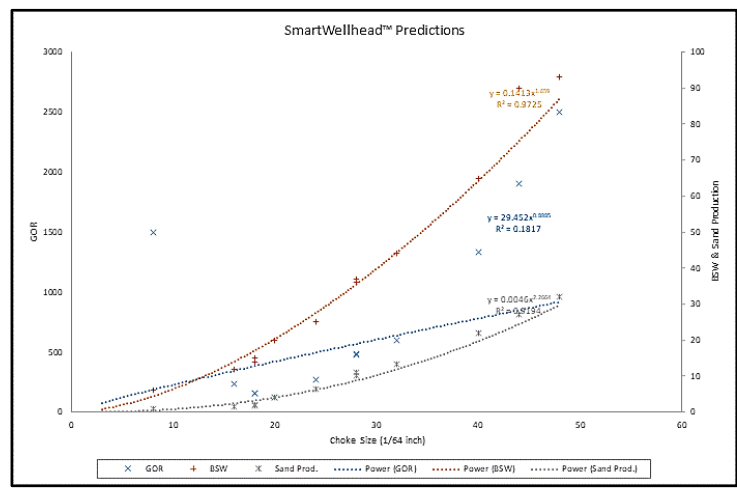

Fig. B-3. Power plots for big data model.

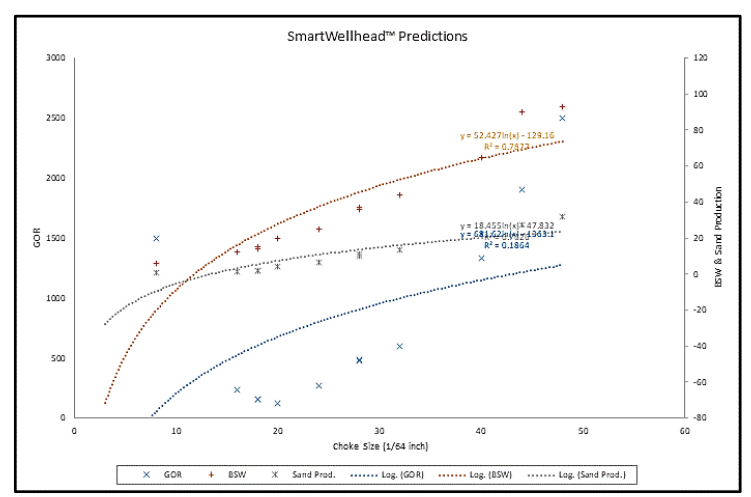

Fig. B-4. Logarithmic plots for big data model.

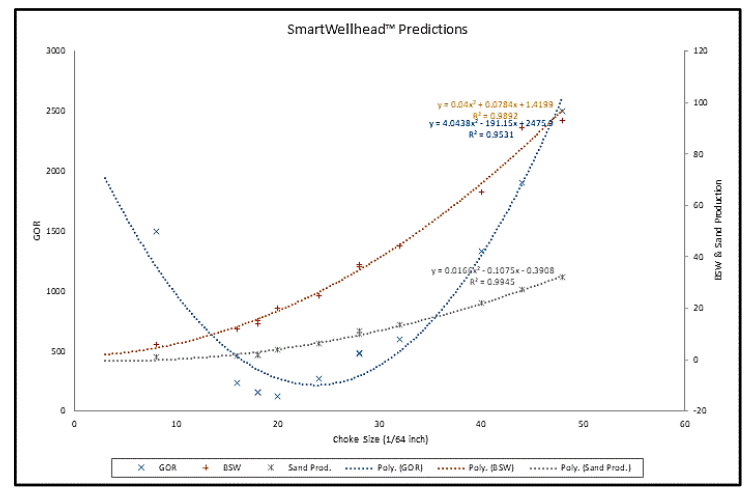

Fig. B-5. Polynomial plots for big data model.

\section{FUNDING}

This project was partially funded by the World Bank Centre of Excellence, University of Portharcourt, Rivers, Nigeria.

\section{ACKNOWLEDGMENT}

We express heartfelt gratitude to Prof. Joseph Ajienka, Prof. Francis Fusier, Institute of Petroleum Studies University of Portharcourt, family, friends and Total E \& P Nigeria Limited. Special thanks to the Almighty God for the foresight, zeal, grace, capacity and understanding to carry out this project.

\section{REFERENCES}

[1] Ajienka, J.A, Enaibe, O.E and Owolabi, O.O (1994). Multiphase Flow Metering (An Evaluation of Discharge Coefficients). The Journal of Canadian Petroleum Technology, 33, 1 - 7 .

[2] Jansen, J.D. (2001). Smart Wells. Contribution to the "Jaarboek" of the "Mijnbouwkundige Vereeniging", $1-11$.

[3] Van den Hoek, P.J. and Geilikman, M.B. (2006). Prediction of Sand Production Rate in Oil and Gas Reservoirs (Importance of Bean-up Guidelines). Russian Oil and Gas Technical Conference and Exhibition, Moscow, 1 -15.

[4] Kittilsen, P., Fjalestad, K. and Aasheim, R. (2014). Stabilized and Increased Well Production Using Automatic Choke Control. International Petroleum Exhibition and Conference, Abu Dhabi, pp. 1 -10 . 